\title{
Investigating the Relationship between Agility and the Reputation of Organization's Brand in Technical and Engineering Services Firms (A Case Study: The Employees' Perspectives on the Consulting Industrial Meta-Research Sepahan Firm)
}

\author{
Hosein Majlesi \\ EMBA, Managing Director of SBR engineering company \\ Hosein.Majlesi@sbr-co.com \\ Zohreh sajjad \\ Ministry of education, district 4 of Isfahan, Iran \\ Zohreh_sajjad@yahoo.com
}

\author{
Doi:10.5901/mjss.2015.v6n5s2p596
}

\begin{abstract}
Agility is a reaction to the existing challenges in a work environment. It dominates an environment by a change and a lack of trust. In fact, agility wants an organization to accelerate merging technology, employees, and relationship management in order to react to the customers' changeable needs in market environment, which are constantly changing and unpredictable. This trend has always been viewed as a luxury not as a practical way in Iranian organizations. On the other hand, being aware of the fact that this variable can be influential in the organization's outputs such as the customers' perspectives towards the firm and its reputation among those customers, the variable will double in importance. Nowadays, reputation is considered as the main criterion for firms and people. The organization's managers, critics, and supporters use the firm's reputation and brand in order to show their evaluation and perception. Due to this, the organizations are concerned about gaining and enjoying a good reputation efficiently because, through different ways, they have got cognizant of the relationship between brand reputation and different aspects of the organization. Regarding this matter, the present study aims at investigating the effect of organizational agility on the organization's brand reputation in the technical and engineering services firms in order to suggest useful strategies to the organization's managers. The population of the study consists of all the employees inconsulting industrial meta-researchlsfahan firm. Regarding the obtained standard deviation out of the first questionnaire, the maximum volume of the estimated sample in the error of \%5 equals 93 individuals in which after distributing 115 questionnaires, 106 completed questionnaires were collected. After designing the research primary model, in order to analyze the data, using AMOS software, the structural equation was employed.Comparing the fitness indices within an acceptable range, we can acknowledge that all the indices of the final model enjoy the desired values and the final model is confirmed. Therefore, the research main hypothesis suggesting that the organizational agility has an effect on the reputation of the organization brand in consulting industrial meta-researchSepahanfirm is accepted. The amount of this positive effect in non-standard mode equals 0.97 whereas in standard mode this amount reduces to 0.45 . On the other hand, among all the aspects, competence and flexibility respectively have the most effect on the reputation of the organization brand.
\end{abstract}

Keywords: Organizational Agility, Reputation of the Brand, Technical, and Engineering Services Firms

\section{Introduction}

Over the past decade, the organization's success has depended on their ability in recognizing customers' needs and providing quick and cheap services. Nowadays, "agility"1 as a dominant business paradigm in the third millennium and the best alternative for the organizations' survival has attracted the attention of all the production and service organizations. Followed by this, efforts to reach a desired level of agility in the organizations have been made (Alves et al, 2012). In recent years, due to the changes in modern technology, we have witnessed the flourishing of a new concept named agility as a significant approach in business, whose goal is to develop an organization's flexibility when confronted with a new situation. Generally, the definitions of agility make the organization dynamic, situation-based, changeable, and growth-oriented (Bottani, 2009). The reason for a tendency to dynamism is that the conditions under which an organization reaches agility may not be influential for a different period of time (Bagherzadeh et al, 1389). Also, the reason for being situation-based is that the market environment influences the required level of agility. However, agility is only obtained through the coherence of customers' hierarchy of needs in internal and external environment of the 
organizations' context. This is possible by having a holistic perspective towards the organization's advanced technologies along with internal capabilities, which process those technologies, as well as using technology of information systems (Ramesh \&Devadasan, 2009). Agility constantly pays attention to the performance of the personnel and organization, the value of the product and services, and a constant change in the opportunities obtained out of attracting customers. It also requires a permanent readiness for facing fundamental and superficial changes. Agile organizations are always ready for learning anything new, which leads to an increase in benefits because of using new opportunities (Chan \& Tong, 2009). Moving to agility is adjusted by assuming a share in profitable markets coupled with complete information and services and the products suited to the customers' needs are identified (Colombo \& Harrison, 2008). Therefore, agile and successful rivals not only should gain a great recognition of the markets, production lines, qualifications, and their existing customers very well but also should recognize the customers and their future potential markets. This recognition leads to strategic programs in order to acquire new qualifications, developing production lines/new services, and recording as well as storing new markets. In these investigations we would like to study the relation between brand and agility in engineering consultancy companies because generally if the brand and experiences of this type of companies are high, the agility will be low.

Due to the effect of internet on organizational agility and the formation of foundations of modern economics for the sake of achieving the goals of modern marketing, agility has shifted to a key factor in competition between international markets. The name of brand's firm is one of the factors, which has been under its influence but has not kept the researchers' attention so far. From the perspective of Ewing et al (2010), the firms have now realized the role and importance of the organizational reputation regardless of their location. The current researches on organization's reputation have mostly concentrated on the structural definition of reputation, i.e. a method that makes reputation operational and this is ultimatelyevident in the customers' and the organization's success. The organizational reputation is more than the firm's image and identity and has great advantages such as decreasing the operational costs, the customers' high rate of return and constantly a sales rise and the possibility of rising the products' costs (Inglis et al, 2006). It is impossible to perceive the organizations' reputation without an awareness and recognition of complicated concepts, beliefs, and existing interpretations about the firm. In addition, these interpretations, beliefs, and concepts are unstable and unpredictable which highlights the importance of a further recognition of factors influencing reputation. Looking at the firm's income, we can observe its reputation value. Whenever the brand's reputation increases, the sales also increase. However, we should acknowledge that reputation is fragile and might be lost easily and when it is lost, one should make considerable efforts to return it. In fact, returning reputation is seven to ten times more difficult than gaining it (Hodoric et al, 2011). The fact is that most of the valuable assets of the firms are not their tangible asset (such as facilities, land, and buildings, etc.), but their intangible assets (management ability, marketing, financial and operational expertise, and most important of all, brand's equity and reputation) that can add value. Whenever the brand's equity and the factors influencing a firm's reputation are accurately measured, there will be a main criterion for evaluating the effects of the marketing's long-term decisions. The firm's reputation leads to further income, lower costs, and more benefits by itself and can have direct effects on the organization's ability in making right decisions. It can also affect marketing communications and success in commercial development in the case of an increase in the products' costs (Moghbelet al, 1387). One of the duties of the senior management in every kind of organization is to create strong brands, which improve the power of their capabilities while fulfilling their promises and commitments. Therefore, these brands lead to a reputation for their organizations. By making conceptual distinctions between the products via branding, gaining reputation, and increasing the number of loyal customers, they create values beyond financial benefits for the organization. These values are the brand's equity or an improvement in the public image of the organization (Greyser, 2009). Technical and engineering services contractors are in need of the development of their brand's reputation in employer organizations in order to gain an advantage in the competition for developing projects. In this study, we will investigate the effect of organizational agility on this reputation. In other words, we will investigate which dimensions of organizational agility can influence the development of the brand's reputation more. The results of this research prevents managers from paying high costs for developing agility in thesections, which do not influence reputation.

\section{An Introduction to Concepts and Literature Review}

\subsection{Organizational agility}

Agility is a full capability for business unit, which consists of organizational structures, information systems, and support processes. Agility, as a production/service philosophy, welcomes those organizations, which compete in all sectors. The only way by means of which agility can be gained is through a coherence of the customers' needs hierarchy in internal 
and external environmental contexts. This is possible by adopting a holistic perspective towards the organization's advanced production technologies (Bottani, 2009). Using information technology in relationships with customers and supply chain has been introduced as the key to successfor organizational agility. The agility of the whole chain can lead to organizational agility. In their study, DeGroote and Marx (2013) investigated the effect of information technology on the chain agility and the firm's performance. The researchers used the ability of being sensitive and responsive to the market's changes in order to measure the agility of the supply chain. The results of this research on 193 American manufacturing firms suggested that information technology improves the supply chain's ability of being sensitive to the market's changes through competency, precision and accuracy, availability, and punctuality of the chain members' information. The researchers also realized that information technology increases the supply chain's ability in responding the market's changes through decreasing the costs, improving the quality, and on time development of the product. The researchers finally realized that increasing the supply chain's agility through information technology leads to a positive effect on the firm's sales, market share, profitability, quick response to the market, the customers' satisfaction, and an overall improvement in the firm's performance.

In his study, Liu et al (2013) investigated the effect of information technology on the firm's performance through moderating variables of agility and absorbing capacity. After designing and presenting the model, the researchers tested the model and reached the conclusion that the agile supply chain and absorbing capacity have an effect on information technology quite moderately and lead to the organization's better performance. The conceptual model of this research is represented in Figure 1:

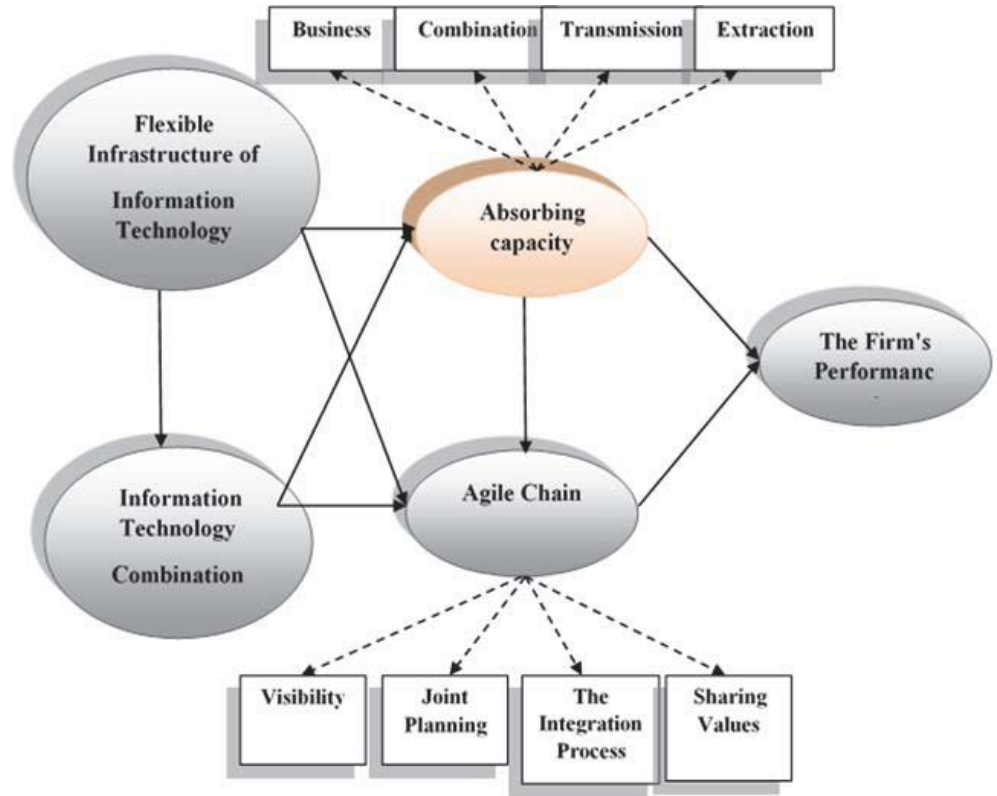

Figure 1. The research conceptual model (Liu et al, 2013)

Gligor\& Holcomb (2012) investigated the logistic capabilities on the agility of the chain. Investigating the literature review related to the agility of the supply chain during the years 1991 to 2010, the researchers found that most scholars in the field recognize the agility of the supply chain by components such as flexible production, the speed of supply chain, and pure production. They also put great emphasis on these components. The researchers found that there are gaps such as the ability of managing demand and supply, integration capabilities, measurement and transaction capabilities, and sharing information using technology information. In this regard, they removed this gap by presenting the model of chain supply agility based on logistic capabilities. The model is represented below: 


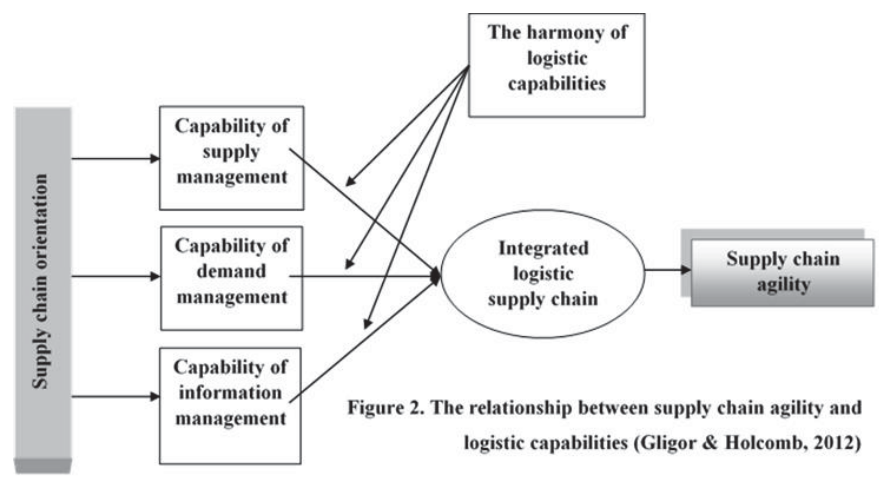

Chan and Tong (2009) presented a conceptual model for accepting the agility methodologies. First, by studying the literature review related to the models of agility acceptance in organizations and comparing them with each other, they gained a general perspective in the field. Then, they raised the process of knowledge management in organization as a new perspective for accepting the agility methodologies and presented a conceptual model for their perspective, whichis presented below. They claim that the presented model can be useful in understanding the quality of accepting agility.

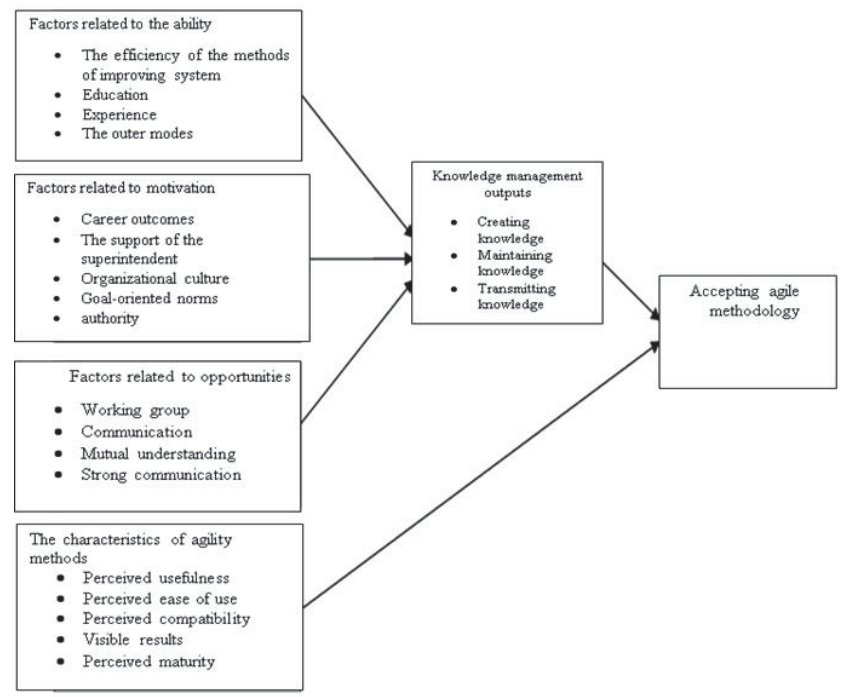

Figure 3. Factors influencing the acceptance of agility methodology

Nath and Standing (2010), in another study, investigated the stimuli of applying the information technology in supply chain. In this study, they illustrated ten main stimuli: Decreasing the total costs in supply chain, decreasing the delay time in the chain, improving the quality of information, enhancing operational capabilities, making better relationships with trading partners, having online access to the information, better decision making, delivery and service providing of high quality, developing markets, sharing the risk with trading partners. Investigating some of the experts in different industries. They believe that using information technology in supply chain of aerospace, telecommunications, and automotive industries is of greater significance and without using information technology, these industries would face problems in their competitions (Nath\& Standing, 2010).

Another study has investigated the effect of information technology in supply chain as a tool for improving organizational agility (Vinodh, et al, 2010). Supply chain in an industrial organization will have competitive capability 
whenever it is agile and has competitive and capable components i.e. the supply chain of a company has competitive suppliers who possess international competitive capabilities and the chain has agility concepts. In this regard, modern information technology significantly contributes in order to gain agility. In this study, we present 27 variables overall for managing supply chain. These variables are divided into two categories of independent and dependent variables. Independent variables are proposed in 7 main factors. These variables exist in all the firms, which possess agile supply chain. However, in investigating dependent variables, supply chain has been investigated in two kinds of firm: More agile and less agile (firms). The analysis of this study indicates that recognizing their own conditions, the firms should concentrate on the key aspects of the supply chain of their agility and try not to apply the sole theoretical topics of agility. Even if they seek higher degrees of agility, the innate complexity of many international supply chains makes it more impossible to actualizing this vision. The possibility of having agility is latent in applying information technology (Vinodh et al, 2010).

\subsection{Brand's reputation}

By reputation, we mean the overall perceptions towards a firm's characteristics or brand. Enhancing the brand's reputation is more than maintaining the customers' satisfaction. In fact, it involves all properties a firm gains during the time and different groups of people carry out their evaluation of the brand via these properties. In cases of lack of attention to the market's signals, the reputation gradually decreases which suggests the brand's pressing need for an understanding of the market's everyday concepts (Veloutsou\&Moutinho, 2009).Boo et al (2009) in another study, in America, titled "the brand's equity model and the customer-based reputation and its application in multi purposes", investigated the experimental information for developing a brand model using brand's equity models and customer-based reputation, and ensure the validity and reliability of the model. In the process of doing the research, a proposed as well as a corrective model, in a group of American tourists, were investigated. The results of the research put emphasis on the brand's equity and the firm's customer-based reputation. Besides, it shows that being aware of the brand has a positive effect on the experience of making use of the brand. The results also indicate that the experience of making use of the brand has a positive effect on the firm's reputation but it cannot have a direct effect on customers' loyalty to the brand. In other words, a tourist who has a positive experience might not necessarily be a loyal customer.

Orth and Green (2009), in their study, titled "A comparison between customers' loyalty in family business and nonfamily business: The role of firm's reputation, trust, and satisfaction", reached the conclusion that the firm's reputation influences the customers' loyalty directly and indirectly (via satisfaction). The customers' satisfaction is also directly under the influence of the perspective of the firm and its reputation and indirectly under the influence of trust. In addition, the findings show that there is no difference in customers' loyalty in family business in comparison with nonfamily business. In a research titled "the customer-based brand's equity for a special purpose", the researchers introduced and investigated the customer-based brand's equity in order to gain reputation in tourism industry. The results of the research suggest that there is a positive significant relationship among the four dimensions of customer-based brand's equity. The study of this model of research, the same as the previous researches, emphasizes the significance of the perspective towards the firm and reputation. However, the researchers suggested that this perspective and reputation is not the only vital dimension of customer-based brand's equity, but for a more proper evaluation of the equity models and the firm's reputation, different dimensions such as awareness, quality, and loyalty should also be taken into account. In this study, the concept of brand's equity in two separate markets in Slovenia were investigated and the results indicated that the two dimensions of brand and firm's reputation in the two markets are different from each other (Konecnik\& Gartner, 2007).

In another study, the researchers investigated the effect of the bank's reputation on the perceivedvalue of organizational buyers. The research hypothesis was as the following:

$>$ The firm's reputation has a positive and significant effect on the perceived value of organizational buyers.

- Enjoy a good reputation in comparison with other banks

- Enjoy a good reputation in the total market (Hodovic, et al, 2011)

Regarding the fact that reputation is multidimensional and can be investigated in different fields of science, Moghbel, et al (1387), in their study, looked for a common definition ofthe concept and presented a model for the banks to gain their own brand's reputation. New structures and relationships of this model are as the following: Firm's identity integration, the perspective towards the firm, organizational culture, social duty, crisis management, and the stakeholders' action. The researchers investigated the following hypotheses:

$\mathrm{H} 1$ : In order to make the brand reputable, we should look at the firm's image, and in order to create an image, we should look at identity integration.

$\mathrm{H} 2$ : In order to gain reputation for the firm, the rivals' reputation and environmental factors are all influential factors. 
H3: Crises management, playing social roles, environmental factors, and stakeholders' action all influence the firm's image.

H4: The significance of reputation-making components is different in stakeholders' groups.

The population of this research has been seven large Iranian banks. After data analysis, the first hypothesis was accepted, the second one was rejected, and the third and the fourth ones were accepted, respectively.

The researchers, in another study, using Aaker model, which measures the brand's equity and the firm's reputation, measured the firm's reputation and the brand's equity of active institutions in food industry. In order to do this, first, using Aaker model, they designed a questionnaire consisting of 8 dimensions and 26 questions and distributed them among the customers in food industry. These 8 dimensions are:

Table 1. Reputation dimensions and the brand's equity (Source: Najaf Beigi and Ardeshiri, 1389)

\begin{tabular}{|l|l|}
\hline $\begin{array}{l}\text { Customers' satisfaction and decreasing the changes and the concordance of a product with another product and services } \\
\text { have been predetermined. }\end{array}$ & Quality \\
\hline $\begin{array}{l}\text { Leadership is a function consisting of inspiring the audience, leading the others, choosing the most effective } \\
\text { communication networks, settling the disputes, and maximizing the effects. }\end{array}$ & Leadership \\
\hline $\begin{array}{l}\text { Maintaining a deep loyalty to purchasing or a second selection of the product or provided service in the future, although the } \\
\text { situational effects and the marketing potential attempts can cause a change in the customers' behaviors }\end{array}$ & Commitment \\
\hline The cash price which the customer pays in order to gain a obtain a commodity or service & Price \\
\hline The degree of the actual performance of a firm to satisfy the customers' expectations. & Satisfaction \\
\hline $\begin{array}{l}\text { A feature through which a product is related to a group of products or customers or a particular producer or is distinguished } \\
\text { from the products of other groups. }\end{array}$ & Identity \\
\hline $\begin{array}{l}\text { Consisting of a category of required value-increasing and non-value activities in order to provide the product or a group of } \\
\text { products to the customers who use similar resources. }\end{array}$ & Perceived value \\
\hline Expressing opinions or particular information about the customers' wanting & Advertisement \\
\hline
\end{tabular}

In this study, the researchers investigated the reputation of four firms;Takmakaron, Pegah, Shirinasal, and Mehram from customers' point of view. The results of data analysis indicated "using the brand's advantageous capabilities and eight dimensions influences the brand's reputation and promotion of firms and increases the brand's equity and reputation of the institutions". Also, in a comparison of brand's reputation and equity, Shirinasal has won the first rank among the other firms due to the variety of products and quality. Takmakaron has won the second rank and has gained reputation among the customers due to the variety of products and packing. Mahram is the third reputable firm among the customers since they know its advertisement more than the quality of its products and due to different issues, Pegah is not reputable among the customers and has won he fourth rank (Najaf Beigi\&Ardeshiri Cham, 1389).

Vazifehdoost, et al (1388) have done a research aimed at investigating the effect of brand's extension strategy on the image of services firms among customers in Pasargad bank and some other subsidiary firms with the Pasargad brand (Pasargad insurance company, Pasargad international trade company, Pasargad electronic payment services company, Pasargad brokerage company) in Tehran. The model they designed in their study is represented below:

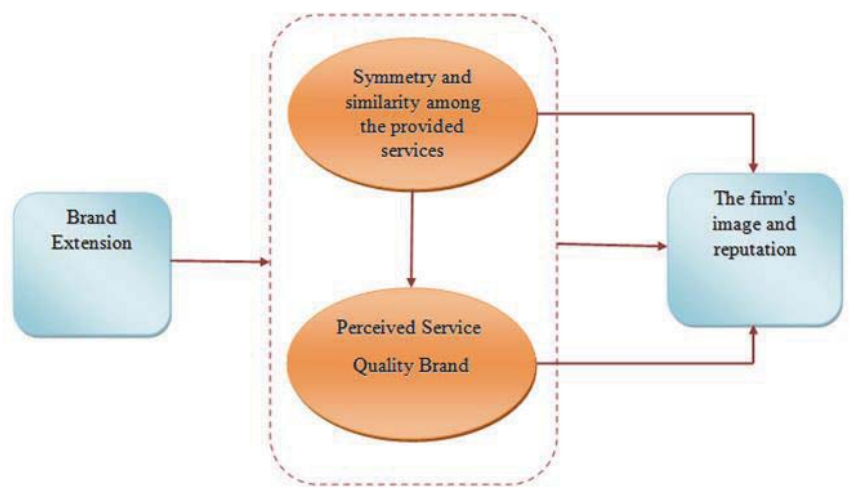

Figure 1. The relationship between the reputable brand extension and the firm's image (Source: Vazifehdoost, et al, 1388) 
The most important results obtained through this research is that employing the strategy of brand extension i.e. using a brand, which provides a service in order to provide new services, influences the reputation and the brand's image in the customers' minds. In this regard, if there is a symmetry among the services provided by the firm i.e. the kind and the area of provided services is in the same category, and also the quality perceived through the provided services brings the customers satisfaction, it will cause an increase in reputation, image, and the trading brand among customers.Because after using the provided services, the customers, paying attention to the degree of satisfaction and perception of these services will gain a perspective towards the trading brand, which leads to creating an image for them. If this image is positive, it will lead to the customers' encouragement to make use of that new service and it will also encourage the others to use these services and lead to an increase in reputation and a promotion in brand.

Ghasemi (1389), in another study, investigated the reputation risk and managing this risk, using capital budgeting during the years 1385 to 1389 in national Iranian gas company. The sample under investigation in this research has been seven Iranian refinery gas. The particular question the researcher seeks an answer for is that: Have economic situations and the components of independent variables in the last five years imposed a considerablereputation to national Iranian gas company?

The independent variables in this question are the amount of absorption of foreign investment, implementation of article 44, the world's financial and economic crisis, the infrastructures of gas industry, the technology used in gas extraction, social security, the success of projects and designs according to the predetermined schedule and budget. The dependent variables are the reputation and validity of the national Iranian gas company in order to do projects and provide services. Investigating the independent variables, the researcher reached the conclusion that:

Absorption of foreign investment: The firm's reputation and validity risk has considerably increased by decreasing foreign investment during the years 84 to 87 .

Submission: The submission of state firms to private sector according to the article 44 and presenting better and more private services by these firms decreases the firm's reputation and validity risk.

Technology: This variable has a positive effect on the firm's risk and reputation. Using technology, national Iranian gas company tries to control and decrease the risk of population by spending budget and dedicating suitable plans in order to construct the faculty of oil and gas in Booshehr.

The success rate of the projects: This variable has high impact on the risk of population because it is tangible and quantitative.

The financial and economic crises: An increase in these crises in the recent years causes a decrease in the degree of foreign investment in this country and increases the risk of population. As it was indicated in the literature review of the research, none of the previous studies have investigated the effect of the organizational agility and the organization's brand reputation so far. The present study was done in order to fill this gap.

\section{Methodology}

Since this research has been done in an actual, objective, and lively (dynamic) organization and one can make use of the results operationally, this study is practical. On the other hand, in most of the humanities researches, descriptive method is used. Descriptive studies consist of a set of methods whose goal is to describe a particular population. Doing these researches, one can further recognize the existing conditions and make use of this recognition in decision-making. Therefore, regarding this, we can point out that the present study is a descriptive/analytic research of the survey-type. Data collection was done through questionnaires. The most comprehensive questionnaire the researchers have developed is in a relationship with the factors influencing organizational agility by Sharifi\& Zhang (1999) in four main dimensions, which are accountability, competency, and speed (quoting from Bagherzadeh, et al, 1389). On the other hand, the brand's reputation questionnaire is adopted from a PhD dissertation in Ohio University, America (Long-Tolbert, 2000) which has 26 indices and 7 main dimensions which are the firm's characteristics, social duty, social utility, financial indexes of the product/service, the personnel qualifications, leading and management state.

\subsection{Population and sample:}

The sample of this research consists of all the members of consulting industrial meta-research Isfahan firm who are about 186 people. This firm provides basic and detailed design engineering services in the areas of building, structures, electricity, automation, architecture, mechanics, installation, supervision and inspection services, technical inspection, engineering services, and contracting scheme and construction in transferring systems of material, lime, dolomite, steel, and etc. In this study, due to the lack of access to the personnel, the method of sampling in finite population has been 
used.

$$
n=\frac{N \times Z_{\alpha / 2}^{2} \times \delta^{2}}{\varepsilon^{2}(N-1)+Z_{\alpha / 2}^{2} \times \delta^{2}} \quad \Rightarrow \quad n=\frac{186 \times(1.96)^{2} \times 0.347^{2}}{0.05^{2}(185)+(1.96)^{2} \times 0.347^{2}}=93
$$

In order to determine the standard deviation, a preliminary sampling has been used. In this regard, a questionnaire was randomly distributedamong the personnel and managers. Studying the standard deviation, the results of the questionnaire suggested that the highest standard deviation in the population equals 0.347 . Therefore, regarding the obtained standard deviation, the maximum estimated volume of the samplewith the error of \%5 equals 93 people. After distributing 115 questionnaires, 106 completed questionnaires were collected and therefore, these 106 questionnaires are thebasis of the statistical analyses of this study.

\subsection{The analysis of data}

In order to analyze the data, after codifying the primary model of research, thestructural equations using AMOS software was used. The primary model is as the following:

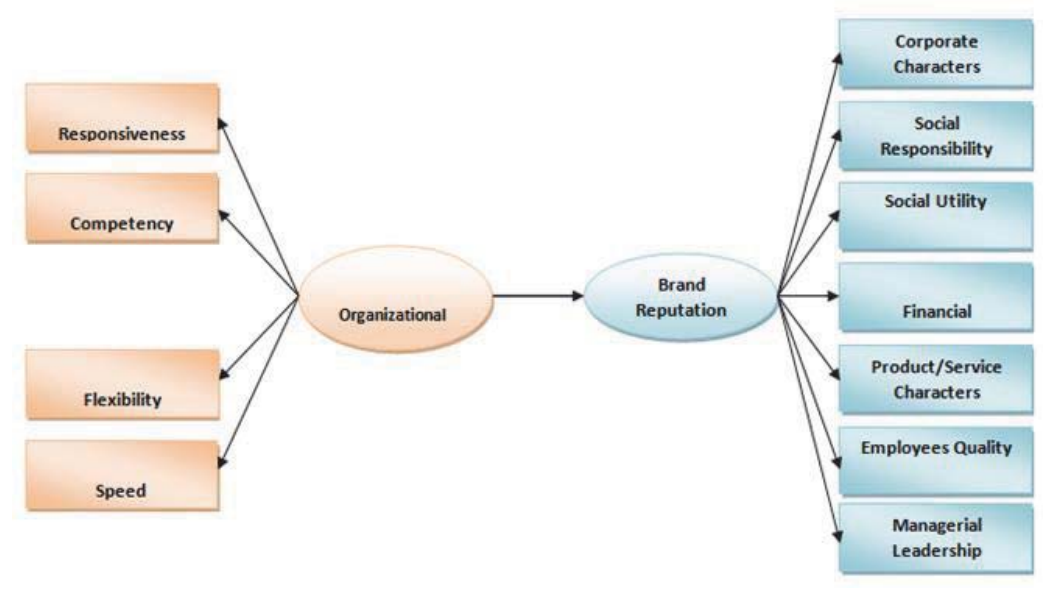

Figure 5: The conceptual model of the research

The structural equations are one of the new statistical methods as well as one of the most efficient methods of multivariable analysis. Their main application is in multi-variable themes which we cannot develop with two variables; each time considering one independent variable with a dependent one. The multi-variable analysis refers to a set of methods of analysis whose main characteristic is to analyze several independent variables with several dependent variables simultaneously (Human, 1384). The structural equations as a statistical pattern investigates the relationship between latent and manifest (observed) variables and is usually referred to as SEM or Structural Equation Modeling but some people refer to that as structural analysis of covariance, LISREL modeling. Using structural equations, we can confirm the overall hypothetical structures or patterns with non-experimental data. The structural equations provide a coherent framework in order to investigate the power of relations between all the variables of a theoretical model. The theories aremajor axis in this pattern and we cannot give an accurate description of the internal relationship between the variables. The structural equation is a multi-variable analysis technique from multiple regression family, which provides the possibility of testing a set of regression equations simultaneously. In fact, the structural equation modeling is a comprehensive statistical approach in order to test hypotheses about the relationships between observed and latent variables. In the model of structural equation, the methodology is as the following:

1. Specifying a model based on a theory:

The pattern or model of a statistical equation is about the relationship between variables. These patterns take different forms in different analytic approaches. For example, while multiple regression and variance analysis show the models with directional relationships among the variables, a model about correlation usually indicates the non-directional 
relationships as mutual relationships between two variables. At this stage, a pattern or model is obtained based on interpreting a theory into structural or mathematical equations i.e. first we draw the track diagram and show the relationships between variables. After specifying the latent variables, we must choose the indices or appropriate observed variables and connect to those variables. For measuring the latent variable, it is better to use several indices instead of one and this is done with the help of a conceptual and operational definition (Human, 1384).

1. Evaluating the setting mode of the model or pattern: It is based on that the model must require the conditions for obtaining a unique solution for the mentioned parameters.

2. Providingestimates for the proposed pattern: Making estimatesof free parameters from the total of observed data consisting of repetitive processes; in each repetition, an implicit covariance matrix is built and compared with thatof the observed data. Comparing these two matrixes leads to producing a remaining matrix and these repetitionsgo on until the remaining matrix reduces to its minimum.

3. Evaluating the symmetry or fitting of the pattern or model: There is a symmetry between the pattern or model and the observed data whenever the implicit covariance matrix equals the covariance matrix of the observed data i.e. the matrix is near zero. The most significant step in this stage is to check the total criterion of the model's asymmetry and the testing capability of the evaluation mode to see if reforms are required or not. Whenever a model is estimated, the software releases a series of statistics such as standard deviation etc. about the evaluation of the model's asymmetry with the data.

4. Reforming the model: Adjusting the mentioned and estimated model through releasing the parameters, which were already fixed, or making those parameters, which were already fixed, free.

5. Interpreting the model: If the symmetry tests show that a model is adequately in concordance with the data, in this stage, we concentrate on the identified factors (the model parameters) of the concordant model. In this stage, the meaningfulness of the model's parameters are evaluated.

\section{The Research Hypotheses}

\subsection{The major hypothesis:}

The organizational agility has a significant effect on the organization's brand reputation in technical and engineering services firms.

\subsection{The subsidiary hypotheses:}

1. The accountability dimension of the organizational agility has a significant effect on the brand's reputation.

2. The competence dimension of the organizational agility has a significant effect on the brand's reputation.

3. The flexibility dimension of the organizational agility has a significant effect on the brand's reputation.

4. The speed dimension of the organizational agility has a significant effect on the brand's reputation.

\subsection{The validity and reliability of the questionnaires:}

Although the validity and reliability of both questionnaires were proved in the previous studies, because the questionnaires were tested in a new environment, the reliability of both questionnaires was confirmed using Cronbach Alpha and the validity was confirmed using KMO and Bartlett tests. These are shown in the following Tables:

Table 2: Cronbach Alpha Coefficient for measuring the reliability of the questionnaires

\begin{tabular}{|c|c|l|}
\hline N of Items & Cronbach's Alpha & Index \\
\hline 21 & .826 & Organizational Agility \\
\hline 26 & .793 & Brand Reputation \\
\hline
\end{tabular}

Table 3. KMO and Bartlett tests coefficient for measuring the validity of the questionnaires

\begin{tabular}{|c|c|l|}
\hline Sig & KMO \& Bartlett's Coefficient & Index \\
\hline 0.000 & .761 & Organizational Agility \\
\hline
\end{tabular}




\section{The Research's Findings}

In order to fit the model of the research, the structural equations and AMOS software were used. The results of the model fitness were indicated in standard and non-standard coefficients in Figures 6 and 7.

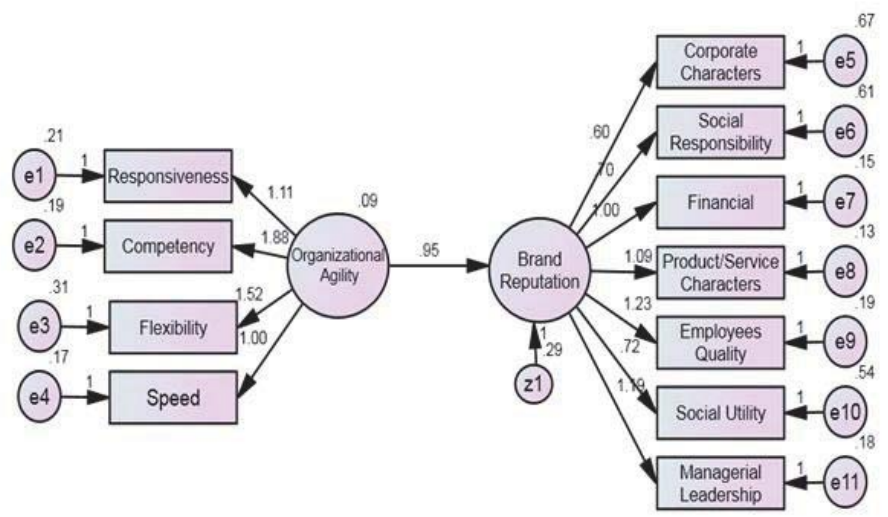

Figure 6: Non-standard coefficients of the model

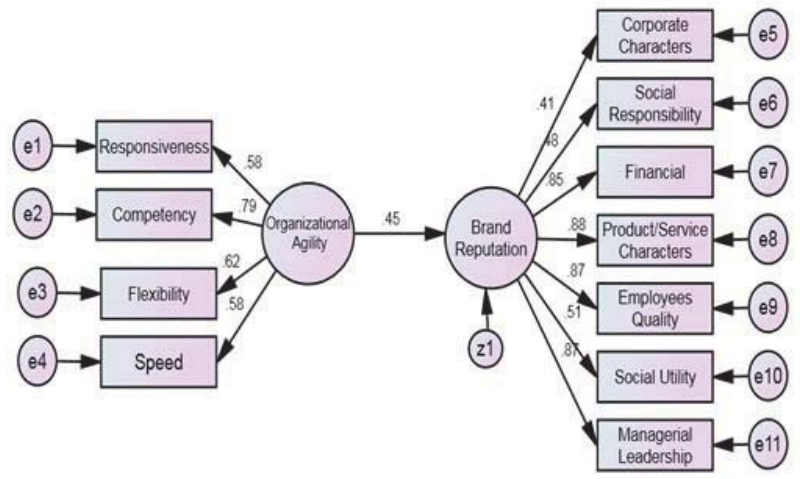

Figure 7: Standard coefficients of the model

The results obtained through investigating the meaningfulness of the estimated track coefficients in the above model are represented in Table 4.

Table 4: The meaningfulness of the track coefficients

\begin{tabular}{|cccc|ll|}
\hline P & C.R. & S.E. & Estimate & & \\
\hline$* * *$ & 5.040 & .188 & .948 & ORGANIZATIONAL AGILITY & <--- Brand Reputation \\
& & & 1.000 & Brand Reputation & <-- FINANCIAL \\
$* * *$ & 16.888 & .065 & 1.093 & Brand Reputation & <-- PRODUCT/SERVICE CHARACTERS \\
$* * *$ & 16.458 & .075 & 1.233 & Brand Reputation & <-- EMPLOYEES QUALITY \\
$* * *$ & 7.986 & .090 & .720 & Brand Reputation & <-- SOCIAL UTILITY \\
\hline
\end{tabular}




\begin{tabular}{|c|c|c|c|c|c|}
\hline$P$ & C.R. & S.E. & Estimate & & \\
\hline 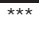 & 16.466 & .073 & 1.194 & Brand Reputation & <--- MANAGERIAL LEADERSHIP \\
\hline *** & 7.367 & .095 & .698 & Brand Reputation & <--- SOCIAL RESPONSIBILITY \\
\hline \multirow[t]{2}{*}{ *** } & 6.207 & .097 & .605 & Brand Reputation & <--- CORPORATE CHARACTERS \\
\hline & & & 1.000 & ORGANIZATIONAL AGILITY & $<---$ Speed \\
\hline *** & 6.603 & .229 & 1.515 & ORGANIZATIONAL AGILITY & <--- Flexibility \\
\hline *** & 7.178 & .261 & 1.877 & ORGANIZATIONAL AGILITY & $<---$ Competency \\
\hline *** & 6.304 & .176 & 1.111 & ORGANIZATIONAL AGILITY & $<---$ Responsiveness \\
\hline
\end{tabular}

As the results show, all the estimated track coefficients are meaningful. On the other hand, the investigation of the fitness indexes of the model suggest that the RMSEA values equals 0.146 and is more than 0.1 . Therefore, the model was again solved by making the proposed reforms using a software. The results of solving the reformed model in the form of standard and non-standard equations are represented in Figure 8 and 9.

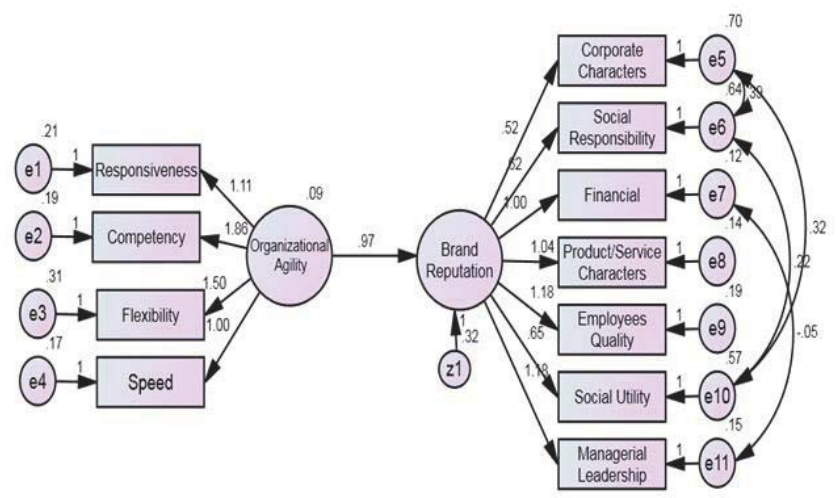

Figure 8: Non-standard coefficients in the reformed model

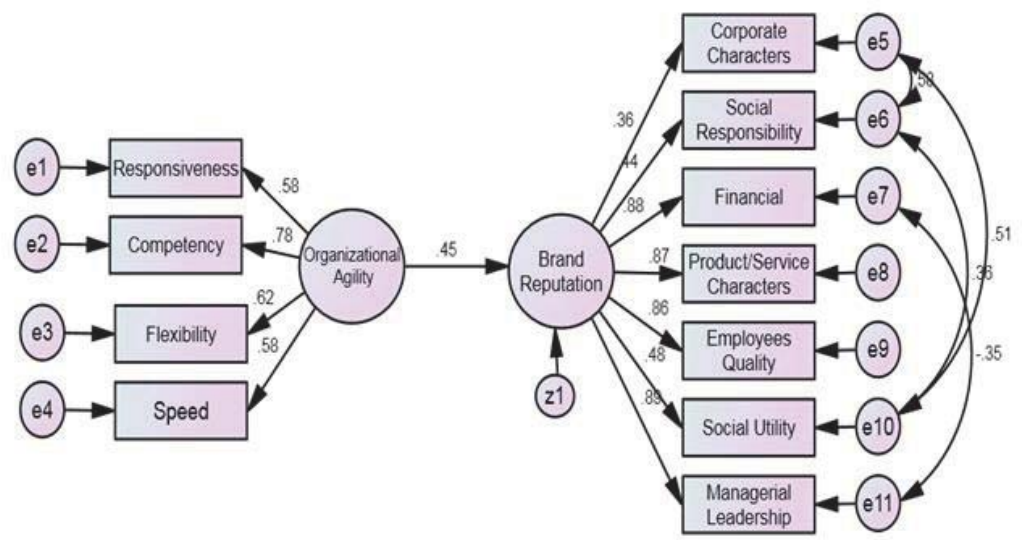

Figure 9: Standard coefficients in the reformed model

The results of the meaningfulness of the reformed model are indicated in Table 5. 
Table 5: The track coefficient meaningfulness of the reformed model

\begin{tabular}{|c|c|c|c|c|c|}
\hline$P$ & C.R. & S.E. & Estimate & & \\
\hline \multirow[t]{2}{*}{ *** } & 5.059 & .191 & .966 & ORGANIZATIONAL AGILITY & <--- Brand Reputation \\
\hline & & & 1.000 & Brand Reputation & <--- FINANCIAL \\
\hline$\star \star \star$ & 17.144 & .061 & 1.042 & Brand Reputation & <--- PRODUCT/SERVICE CHARACTERS \\
\hline *** & 16.952 & .070 & 1.185 & Brand Reputation & <--- EMPLOYEES QUALITY \\
\hline *** & 7.473 & .087 & 647 & Brand Reputation & <--- SOCIAL UTILITY \\
\hline \multirow[t]{2}{*}{ *** } & 16.007 & .074 & 1.181 & Brand Reputation & <--- MANAGERIAL LEADERSHIP \\
\hline & & & 1.000 & ORGANIZATIONAL AGILITY & $<---$ Speed \\
\hline *** & 6.614 & .227 & 1.503 & ORGANIZATIONAL AGILITY & <--- Flexibility \\
\hline *** & 7.201 & .258 & 1.855 & ORGANIZATIONAL AGILITY & <--- Competency \\
\hline 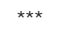 & 6.352 & .175 & 1.113 & ORGANIZATIONAL AGILITY & <-- Responsiveness \\
\hline *** & 6.766 & .091 & .616 & Brand Reputation & <--- SOCIAL RESPONSIBILITY \\
\hline *** & 5.498 & .094 & .516 & Brand Reputation & <--- CORPORATE CHARACTERS \\
\hline *** & 6.637 & .048 & .320 & e5 & <--> e10 \\
\hline *** & 4.947 & .044 & .217 & e6 & <--> e10 \\
\hline .002 & -3.113 & .015 & -.046 & e11 & $<->>$ e7 \\
\hline$\star \star \star *$ & 7.389 & .053 & .389 & e5 & <-> e6 \\
\hline
\end{tabular}

As it can be seen in the above Table, all the estimated track coefficients are meaningful. The indices of the model's fitness are shown in Table 6. After comparing the values of the fitness indices with an acceptable range, we can acknowledge that all the indices have satisfactory values. Therefore, the final model is confirmed and the main hypothesis, which suggests that the organizational agility has an effect on the organization's brand reputation inconsulting industrial meta-research Sepahanfirm, is confirmed. This effect is positive and in non-standard mode, equals 0.97 and in standard mode, it equals 0.45 .

Table 6: The indices of the reformed model's fitness.

\begin{tabular}{|c|c|c|c|c|c|c|l|}
\hline CFI & NFI & TLI & IFI & GFI & RMSEA & $\chi^{2} / d f$ & Fitness symmetry \\
\hline$\succ 0.9$ & $\succ 0.9$ & $\succ 0.9$ & $\succ 0.9$ & $\succ 0.9$ & $\prec 0.1$ & $\prec 5$ & Accepted range \\
\hline 0.938 & 0.911 & 0.913 & 0.939 & 0.916 & 0.079 & 2.976 & Result \\
\hline
\end{tabular}

The results of the effect of the agility dimensions on the brand's reputation are indicated in the following Table.

Table 7: The effect of the dimensions of agility management on the organization's brand reputation

\begin{tabular}{|c|c|}
\hline Brand Reputation & \\
\hline .582 & Responsiveness \\
.782 & Competency \\
.620 & Flexibility \\
.581 & Speed \\
\hline
\end{tabular}

In the above Table, we can observe that all the subsidiary hypotheses of the research are also confirmed and competence and flexibility have the most effect on the organization's brand reputationrespectively. Competence, by itself, has sub-indices such as long-term strategies and strategic perspective, using the solutions for managing change in the organization, having skilled and competent personnel with the knowledge in order to carry out their duties. All these indexes should be the organization's high priority in order to increase the organizational brand reputation via them.

\section{Discussion and Conclusion}

The results of this study indicated that competence should be the high priority of the organization and one of the most 
important indices of which arehaving long-term strategies and strategic perspective. Using the following descriptions is recommended for the organizations of the study in order to gain a good perspective in the first step. This perspective is defined as providing an image of a promising future; a future which is can be long-term in terms of time and from the point of view of the senior managers, designers, and the executives of the organization and the results of which should be positive and in concordance with facilities, capabilities, and resources and shouldalso be practical. Otherwise, these images change into high ideals. Gaining such an image requires planningand establishing an administrative framework in order to achieve the results. In other words, the process of perspective should answer the following questions:

A) What do we want?

This method of planning is used as a link between physical planning and strategic planning. Strategic planning often concentrates on the existing conditions and speaks about the present while the planning perspective broadens the horizonof the planand provides a clear image of the future. The close attention of this plan to future opportunities is the key to success for the plan and its implementation (Nasehifar\& Pour Hoseini, 1387). On the other hand, in competence, the tendency to change is of great importance. In fact, one of the most important obstacles in the way of the agility of virtual organization is the tendency to fixity and resisting change in the organization. In order to remove the resources or the factors causing the tendency to fixity, the following solutions are presented:

Education and relationships: In order to remove resistance, we should communicate with the personnel and the members of the organization and make them understand the reason for making change and number those reasons. If the personnel and members of the organization become aware of all the facts and we clear up any misunderstanding, the resistance will decrease. In order to do this, we can have discussion with the people, issue circulars, andmake speech or reports about them.

Partnership: If people are in partnership when making a change and decision, there is a faint possibility to resistthat change or decision. Before making any kind of change, we should ask anyone who probably disagree with the change and make them participate in decision-making.

Considering facilities: One of the ways by which we can remove the potential resistancein the way of change is to give people something valuable with a reduction in resistance or to eliminate the benefits people getfrom this resistance.

Also, in order to have skilled and competent personnel with required knowledge, it is recommended that the organizations make use of empowerment strategies. Empowerment is providing more freedom, working autonomy, responsibility for decision-making and self-controlling in doing dutiesfor the organization's personnel (McMillan et al, 2011). Employee empowermentisproviding a set of necessary capacities in the personnel in order to make them able to create added value in the organization and play the roles and do their duties with efficiency and effectively in the organization (Li, et al, 2012). Iranzadeh\&Heravi (1389), in an article, investigated and prioritized the influential factors in the personnel's empowerment using TOPSIS method. Finally, the results of the prioritization of the factors suggested that education, employing cooperative system, motivation in the personnel, delegation of authority, reward based on the performance, team work, job enrichment, and the sense of responsibility to empower the employees are respectively in the organization's priority.

\section{References}

Alves, Anabela C; Carvalho, José Dinis \& Sousa, Rui M (2012). Lean production as promoter of thinkers to achieve companies' agility, Learning Organization, The Volume. 19, Issue: 3, pp. 3-17.

Bagherzadeh, M. R., Balooyi-Jamkhaneh, E., \& Moafi-Madani, S. R. (2010). An investigation of agility in governmental organizations ( A case study of Mazandaran Post Office). FasInameye Modiriyat, 7 (18), 37-47.

Boo, Soyoung; Busser, James \& Baloglu, Seyhmus (2009). A model of customer-based brand equity and its application to multiple destinations, Journal of Tourism Management, pp. 219-231.

Bottani, Eleonora (2009). A fuzzy QFD approach to achieve agility, International Journal of Production Economics, Vol. 119. pp. 380391.

Chan, F.K.Y., Tong, Y.L., (2009). Acceptance of agile methodologies: A critical review and conceptual framework, Journal of Decision Support Systems. Vol. 46, pp. 803-814.

Colombo, A.W., Harrison, R., 2008. Modular and collaborative automation: achieving manufacturing flexibility and re-configurability. International Journal of Manufacturing Technology and Management 14 (3/4), 249-265.

DeGroote, S \& Marx, T (2013). The impact of IT on supply chain agility and firm performance: A empirical investigation, International Journal of Information Management, Vol. 33, pp. 909-916.

Ewing, Michael T; Windisch, Lydia \& Newton, Fiona J (2010). Corporate reputation in the People's Republic of China: A B2B perspective, Industrial Marketing Management, Vol. 39, pp. 728-736.

Ghasemi, E. (2010), Lessening the risk of fame in Gas Company of Iran. Fas/nameye Modiriyat va manabee Ensani, 4(12), 161-176.

Gligor, D \& Holcomb, M (2012). Understanding the role of logistics capabilities in achieving supply chain agility: a systematic literature 
review, Supply Chain Management: An International Journal, Vol, 17, No. 4, pp. 438-453.

Greyser, Stephen A (2009). Corporate brand reputation and brand crisis management, Management Decision, Vol. 47 Iss: 4, pp. 590602.

Hodović, Vesna Babić; Mehić, Eldin \& Arslanagić, Maja (2011). Influence of Banks' Corporate Reputation on Organizational Buyers Perceived Value, Procedia Social and Behavioral Sciences, Vol. 24, pp. 351-360.

Hooman, H. (2005). Finding models for structural equations using Lizerel Software. Tehran: SAMT Publications.

Inglis, R., Morley, C., \& Sammut, P, (2006). Corporate reputation and organizational performance: an Australian study, Management Auditing Journal, Vol. 21, No. 9, pp. 934-947.

Iranzadeh, S., \& Babayi-Haravi, S. (2010). An investigation of and prioritization of effective factors on empowering based on TOPSIS (A case study of Gas Company in East Azerbaijan). Farasooye Modiriyat, 4 (13), 59-84.

Konecnik, Maja \& Gartner, William C (2007). Customer - based brand equity for a destination, Annals of Tourism Research, Vol. 34, No.2, pp.400-421.

Li, Chenwei, Keke Wu, Diane E. Johnson, Min Wu, (2012) "Moral leadership and psychological empowerment in China", Journal of Managerial Psychology, Vol. 27, Iss: 1, pp.90-108.

$\mathrm{Liu}, \mathrm{H} ; \mathrm{Ke}, \mathrm{W} ;$ Wei, $\mathrm{K}$ \& Wei, Z (2013). The impact of IT capabilities on fi rm performance: The mediating roles of absorptive capacity and supply chain agility, Decision Support Systems, Vol. 54, pp. 1452-1462.

Long-Tolbert, Sylvia, J. (2000). A conceptual framework and empirical tests of the antecedents and consequences of corporate reputation: A study of consumer markets, PhD Thesis, Presented in partial Fulfillment of the Requirements for the Doctor of Philosophy in the Graduate School of the Ohio state university.

McMillan, Carolyn L. and Maclaren, Andrew C. and O'Gorman, Kevin D. (2011). Commercial hospitality: a vehicle for the sustainable empowerment of Nepali women. International Journal of Contemporary Hospitality Management, Vol.32, No. 2. pp. 189-208.

Moghbel_Baarz, A., Asgari, Gh., \& Khaef-Elahi, A. A. (2008). Devising a model for Iranian banks emphasizing cognitive differences of the beneficial. Fasinameye Modarese Oloome ensani, 12 (4).

Najafbeigi, R., \& Ardashiri, A. (2010). Assessment of capacities of brands in the country's food industry. Faslnameye Oloome modiriyat, 5(20), 111-130.

Naseheifar, V., \& Poorhoseini, S. J. (2008). A comparative study of the writing elements of the statement of missions in local and foreign information technology companies. FasInameye modiriyate danesh, 21(80), 123-142.

Nath, Tanmoy \& Craig Standing, (2010) "Drivers of information technology use in the supply chain", Journal of Systems and Information Technology, Vol. 12 Iss: 1, pp.70- 84.

Orth, Ulroch \& Green, Mark.T (2009). Consumer loyalty to family versus non-family business: The role of store image, trust and satisfaction, Journal of Retailing and Consumer Service, pp. 1-12.

Ramesh, G; \& Devadasan, S. (2009). Literature Review on the Agile Manufacturing Criteria. Journal of Manufacturing Technology Management, $\mathrm{Vol}(18), 182-201$.

Sharifi, Hossein \& Zhang, David., (1999). A methodology for achieving agility in manufacturing organisations: an introduction. International Journal of Production Economics 62 (1-2), 7-22.

Vazifehdoost, H., Saidniya, H. R., \& Kashani, S. (2009). An investigation of the effect of brand development strategy on mental place of service companies ( A case study of Ban and related companies named Pasargad in Tehran). Fas/nameye Modiriyat, 6(16), 4758.

Veloutsou, Cleopatra \& Moutinho, Luiz (2009). Brand relationships through brand reputation and brand tribalism, Journal of Business Research, Vol. 62, pp. 314-322.

Vinodh, S.; Devadasan, S.R. \& C. Shankar, (2010) "Design agility through computer aided design", Journal of Engineering, Design and Technology, Vol. 8 Iss: 1, pp.94 - 106. 